Article

\title{
Intuitionistic Fuzzy Multiple Attribute Decision-Making Model Based on Weighted Induced Distance Measure and Its Application to Investment Selection
}

\author{
Zhengmao Li ${ }^{1}$, Dechao Sun ${ }^{2, *}$ and Shouzhen Zeng ${ }^{3, *}$ \\ 1 School of Finance, Zhejiang Gongshang University, Hangzhou 310018, China; lzm@ctsec.com \\ 2 College of Computer and Information, Zhejiang Wanli University, Ningbo 315100, China \\ 3 School of Business, Ningbo University, Ningbo 315211, China \\ * Correspondence: sundechao123@163.com (D.S.); zengshouzhen@nbu.edu.cn (S.Z.); \\ Tel.: +86-574-86300396 (S.Z.)
}

Received: 11 June 2018; Accepted: 2 July 2018; Published: 4 July 2018

\begin{abstract}
This paper investigates an intuitionistic fuzzy multiple attribute decision-making method based on weighted induced distance and its application to investment selection. Specifically, an intuitionistic fuzzy weighted induced ordered weighted averaging operator is proposed to eliminate the drawbacks of existing methods by extending the functions of the order-induced variables. The main advantage of the proposed operator is its dual roles of the order-inducing variables that can simultaneously induce arguments and moderate associated weights. A further extension of the proposed operator is its adaptation towards measuring intuitionistic fuzzy information more effectively. In addition, a multiple attribute decision-making model based on the proposed distance operators is proposed. Finally, the practicability and validity of the proposed model are illustrated by using a numerical example related to investment selection.
\end{abstract}

Keywords: intuitionistic fuzzy set; multiple attribute decision-making; weighted induced distance; investment selection

\section{Introduction}

The multiple attribute decision-making (MADM) technique is a widely used method in solving real-world problems, in which a variety of attributes are involved to consider from finite feasible alternatives according to the evaluated attributes' evaluation or preference information given by multiple decision-makers. Clearly, fuzziness and vagueness are inevitably integrated into the MADM process due to the vagueness and uncertainty of evaluated objects and the ambiguous nature of human thinking. Intuitionistic fuzzy set (IFS), initially developed by Atanassov [1], has proven to be a powerful and useful tool for processing complex-type information in day-to-day life. The IFS is described by a membership degree $(0 \leq \mu \leq 1)$ and a non-membership degree $(0 \leq v \leq 1)$ that satisfies the condition $\mu^{2}+v^{2} \leq 1$. To date, various MADM methods related to IFS have appeared in well-known publications and conferences. Several authors have conducted valuable scientific investigations and literature reviews on the development of IFS from different viewpoints [2-4].

As one of the important aspects of fuzzy theory, the distance measured between IFSs has received continuous attention for decades in both the theory and application areas. Existing IFS distance measures are mostly investigated from the weighted averaging perspective [5-8]. Recently, Zeng and $\mathrm{Su}$ [9] proposed a new intuitionistic fuzzy distance measure from the ordered weighted viewpoint, namely the intuitionistic fuzzy ordered weighted distance (IFOWD) operator, whose prominent 
feature is that it can incorporate a decision-maker's attitudinal characters into the MADM process. Later, by combining the weighted average and IFOWD methods, Zeng and Xiao [10] developed the intuitionistic ordered weighted averaging-weighted average distance (IFOWAWAD) operator and explored its usefulness in solving MADM problems. More recently, motivated by the induced ordered weighted averaging distance (IOWAD) measure [11], Zeng et al. [12] proposed the intuitionistic fuzzy induced ordered weighted averaging distance (IFIOWAD) measure that enables us to consider the complex attitude of decision-makers using order-induced variables. The essence of the IFIOWAD as well as the IOWAD operator is to enable the decision-makers to incorporate their complex attitude into the aggregation process, using the order-induced variables on the ordered arguments. Thus, the interests of the decision-makers are taken into account during the decision-making process. Although it is a relatively new MADM approach, the induced aggregation distance operator has been successfully applied in various fields of research. Recent literature contains a number of extensions and subsequent applications in MADM problems, as listed in Table 1.

Table 1. Induced aggregation distance methodology in multiple attribute decision-making (MADM) problems.

\begin{tabular}{cl}
\hline Author, Year & \multicolumn{1}{c}{ Induced Aggregation Distance Methodology } \\
\hline Merigó and Casanovas, 2011 [13], & Induced Minkowski ordered weighted averaging distance (IMOWAD) \\
Casanovas et al., 2016 [14] & Induced Euclidean ordered weighted averaging distance (IEOWAD) \\
Merigó and Casanovas, 2011 [15] & Uncertain IOWAD (UIOWAD) operator, Fuzzy IOWAD (FIOWAD) \\
Zeng et al., 2013 [16] & Uncertain IEOWAD (UIEOWAD) \\
Su et al., 2013 [17] & Induced heavy ordered weighted averaging distance (IHOWAD) \\
Zeng et al., 2014 [18] & 2-tuple linguistic IOWAD (2TLIOWAD) operator \\
Li et al., 2014 [19] & Fuzzy linguistic IOWAD (FLIOWAD) \\
Xian and Sun, 2014 [20] & Uncertain IHOWAD (UIHOWAD) \\
Su et al., 2015 [21] & Intuitionistic fuzzy IOWA weighted averaging distance (IFIOWAWAD) \\
Zeng et al., 2017 [12] & Fuzzy linguistic IMOWAD (FLIMOWAD) \\
Xian et al., 2016 [22] & Novel intuitionistic fuzzy IEOWAD distance (NIFIEOWAD) \\
Xian et al., 2017 [23] &
\end{tabular}

It is clearly shown in previous reviews that the existing induced aggregation distance methods, such as the IFIOWAD operator, are popular techniques that have been applied successfully in many real-world problems. However, one can observe that the above-mentioned induced aggregated distances share a similar problem that must be solved: their order-inducing variables are not involved in the actual aggregation of results. As a consequence of this, the results obtained by these distance operators cannot account for the variation derived from a change of the order-inducing variables. The latter issue is especially important whenever variation degrees of property regarding alternative-attribution pairs, such as confidence, consistency or importance, are represented in terms of order-inducing variables and need to be considered. To circumvent this defect, this paper develops a revised induced aggregated distance measure between IFSs, termed as an intuitionistic fuzzy weighted induced ordered weighted averaging distance (IFWIOWAD) operator that takes into account the intrinsic variations in the order-inducing variables during the aggregation process. Further, to enrich the theory and application of the developed IFWIOWAD operator, we propose an intuitionistic weighted induced ordered weighted averaging weighted average distance (IFWIOWAWAD) operator that can integrate the weighted average approach with the IFWIOWAD measure. Therefore, it can address the complex attitude of experts and the importance of attributes in the decision-making framework.

The rest of this paper is structured as follows. In Section 2, some definitions of the IFS and induced aggregation distance operators are reviewed. Section 3 presents the IFWIOWAD operator and explores its main properties. Section 4 develops the IFWIOWAWAD operator, based on which a MADM model is represented in Section 5. An example concerning investment selection is presented in Section 6. In the final section, we summarize the paper's main results. 


\section{Preliminaries}

This section reviews several basic concepts concerning the IFS and the induced aggregated distance methods.

Definition 1. An IFS P in a set $Z=\left\{z_{1}, z_{2}, \ldots, z_{n}\right\}$ is defined as in (1) [1]:

$$
P=\left\{\left\langle z,\left(\mu_{P}(z), v_{P}(z)\right)\right\rangle \mid z \in Z\right\}
$$

where the function $0 \leq \mu_{P}(z) \leq 1$ and $0 \leq v_{P}(z) \leq 1$ denote as the degree of membership and the non-membership, respectively, and satisfy $0 \leq \mu_{P}(z)+v_{P}(z) \leq 1$. For convenient calculation, the pair $\alpha=\left(\mu_{\alpha}, v_{\alpha}\right)$ is signed as an intuitionistic fuzzy number (IFN) [24], where $\mu_{\alpha}, v_{\alpha} \in[0,1]$ and $\mu_{\alpha}+v_{\alpha} \leq 1$.

Definition 2. The intuitionistic fuzzy distance (IFD) between IFNs $\alpha_{1}$ and $\alpha_{2}$ is given by the following formula [9]:

$$
d_{I F D}\left(\alpha_{1}, \alpha_{2}\right)=\left|\alpha_{1}-\alpha_{2}\right|=\frac{1}{2}\left(\left|\mu_{\alpha_{1}}-\mu_{\alpha_{2}}\right|+\left|v_{\alpha_{1}}-v_{\alpha_{2}}\right|\right)
$$

As one of the most widely used and effective extensions of the ordered weighted averaging (OWA) methods [25], the IOWA operator [26] aggregates information by its reordering rule, performed with the order-inducing variables to accommodate a more complicated attitude of decision-makers.

Definition 3. An IOWA is defined as follows:

$$
\operatorname{IOWA}\left(\left\langle u_{1}, a_{1}\right\rangle, \ldots,\left\langle u_{n}, a_{n}\right\rangle\right)=\sum_{j=1}^{n} w_{j} b_{j}
$$

where $W=\left(w_{1}, w_{2}, \ldots, w_{n}\right)^{T}$ is the weight vector satisfying $w_{1}+\ldots+w_{n}=1$ and $w_{j} \in[0,1] . b_{j}$ is the reordered value of $a_{i}$ in the argument $\left\langle u_{i}, a_{i}\right\rangle$ having the $j$ th largest order-inducing variable $u_{i}$.

Based on the work of IOWAD proposed by Merigó and Casanovas [11], Zeng and Su [12] introduced the IFIOWAD operator by combining the advantages of the induced aggregation and the IFD. For IFSs $A=\left(\alpha_{1}, \ldots, \alpha_{n}\right)$ and $B=\left(\beta_{1}, \ldots, \beta_{n}\right)$, it is formulated as follows:

Definition 4. An IFIOWAD operator is defined by a weight vector $W$ with $0 \leq w_{j} \leq 1$ and $w_{1}+\ldots+w_{n}=1$; and an order-inducing vector $U=\left(u_{1}, \ldots, u_{n}\right)$, such that:

$$
\operatorname{IFIOWAD}\left(\left\langle u_{1}, \alpha_{1}, \beta_{1}\right\rangle, \ldots,\left\langle u_{n}, \alpha_{n}, \beta_{n}\right\rangle\right)=\sum_{j=1}^{n} w_{j} d_{I F D}\left(\alpha_{\sigma(j)}, \beta_{\sigma(j)}\right)
$$

where $d_{I F D}\left(\alpha_{\sigma(j)}, \beta_{\sigma(j)}\right)$ is the reordering of $d_{I F D}\left(\alpha_{j}, \beta_{j}\right)$ induced by the decreasing the order of $u_{j}$, and $d_{I F D}\left(\alpha_{j}, \beta_{j}\right)$ is the IF distance between IFNs $\alpha_{j}$ and $\beta_{j}$.

Although the IFIOWAD operator is considered a useful and powerful measure tool, its inherent defect often leads to the loss of information and biased results that can be observed from the following example.

Example 1. Let $A=\{(0.3,0.5),(0.5,0.2),(0.7,0.1),(0.4,0.5)\}$ and $B=\{(0.4,0.6),(0.7,0.4)$, $(0.2,0.7),(0.6,0.2)\}$ be two sections of IFNs, and let the order-inducing variables be $U=(7,8,3,5)$. The main steps for the aggregation of the above arguments based on the IFIOWAD operator are shown as follows: 
1. Calculate the distances $d_{I F D}\left(\alpha_{j}, \beta_{j}\right)(j=1,2,3,4)$ using Equation (2):

$$
d_{\text {IFD }}\left(\alpha_{1}, \beta_{1}\right)=\frac{1}{2}(|0.3-0.4|+|0.5-0.6|)=0.1,
$$

Similarly, we have

$$
d_{I F D}\left(\alpha_{2}, \beta_{2}\right)=0.2, d_{I F D}\left(\alpha_{3}, \beta_{3}\right)=0.55, d_{I F D}\left(\alpha_{4}, \beta_{4}\right)=0.25
$$

2. Reordering the $d_{I F D}\left(\alpha_{j}, \beta_{j}\right)(j=1,2,3,4)$ according to the decreasing values of the variable $u_{j}$ yields:

$$
\begin{gathered}
d_{I F D}\left(\alpha_{\sigma(1)}, \beta_{\sigma(1)}\right)=d_{I F D}\left(\alpha_{2}, \beta_{2}\right)=0.2, d_{I F D}\left(\alpha_{\sigma(2)}, \beta_{\sigma(2)}\right)=d_{I F D}\left(\alpha_{1}, \beta_{1}\right)=0.1 \\
d_{I F D}\left(\alpha_{\sigma(3)}, \beta_{\sigma(3)}\right)=d_{I F D}\left(\alpha_{4}, \beta_{4}\right)=0.25, d_{I F D}\left(\alpha_{\sigma(4)}, \beta_{\sigma(4)}\right)=d_{I F D}\left(\alpha_{3}, \beta_{3}\right)=0.55 .
\end{gathered}
$$

3. Let the associated weighting vector be $W=(0.3,0.4,0.1,0.2)^{T}$, then the aggregation result yields:

$$
\operatorname{IFIOWAD}(U, A, B)=0.3 \times 0.2+0.4 \times 0.1+0.1 \times 0.25+0.2 \times 0.55=0.225 .
$$

If we adjust the values of the order-inducing variables to $U^{\prime}=(8,10,1,6)$, then the aggregation result would be:

$$
\operatorname{IFIOWAD}\left(U^{\prime}, A, B\right)=0.3 \times 0.2+0.4 \times 0.1+0.1 \times 0.25+0.2 \times 0.55=0.225 .
$$

One can be observed that we get the same aggregated results for different values of the order-inducing variables. The reason is that the order-inducing variables in the IFIOWAD operator only play the induced role and are not integrated into the actual aggregation results, thus corresponding aggregation results cannot embody the variation caused by a change of order-inducing variables. In the next section we will develop a new method to overcome this drawback.

\section{The IFWIOWAD Operator}

To solve the feedback problem of the existing IFIOWAD operator, we propose an improved aggregation method, named the intuitionistic fuzzy weighted IOWA distance (IFWIOWAD) operator. It can be formulated as follows:

Definition 5. Let $A=\left(\alpha_{1}, \ldots, \alpha_{n}\right)$ and $B=\left(\beta_{1}, \ldots, \beta_{n}\right)$ be two sets of IFNs. An IFWIOWAD operator is defined by $W$ with $0 \leq w_{j} \leq 1$ and $w_{1}+\ldots+w_{n}=1$, and an order-inducing vector $U=\left(u_{1}, \ldots, u_{n}\right)$, such that:

$$
\operatorname{IFWIOWAD}\left(\left\langle u_{1}, \alpha_{1}, \beta_{1}\right\rangle, \ldots,\left\langle u_{n}, \alpha_{n}, \beta_{n}\right\rangle\right)=\sum_{j=1}^{n} \omega_{j} d_{I F D}\left(\alpha_{\sigma(j)}, \beta_{\sigma(j)}\right)
$$

where $\omega_{j}(j=1, \ldots, n)$ is a moderated weight that relatively depends on weight $w_{j} \in W$ and order-inducing variable $u_{j} \in U$, defined as:

$$
\boldsymbol{\omega}_{j}=\frac{w_{j} u_{\sigma(j)}}{\sum_{j=1}^{n} w_{j} u_{\sigma(j)}}
$$

where $(\sigma(1), \ldots, \sigma(n))$ is any possible permutation of $(1, \ldots, n)$, and clearly satisfies $u_{\sigma(j-1)} \geq u_{\sigma(j)}$ for $j>1$. The distance $d_{I F D}\left(\alpha_{\sigma(j)}, \beta_{\sigma(j)}\right)(j=1, \ldots, n)$ is the reordering of $d_{I F D}\left(\alpha_{j}, \beta_{j}\right)$ induced by $u_{\sigma(j)}$.

Example 2. Assume the same collections of IFNS and order-inducing variables as defined in Example 1. Then the aggregation process by the IFWIOWAD is illustrated as follows: 
1. Record the order-inducing variables:

$$
u_{\sigma(1)}=u_{3}=8, u_{\sigma(2)}=u_{1}=7, u_{\sigma(3)}=u_{4}=5, u_{\sigma(4)}=u_{2}=3 .
$$

2. Calculate the moderated weight $\omega_{j}$ using Equation (6):

$$
\omega_{1}=\frac{w_{1} u_{\sigma(1)}}{\sum_{j=1}^{4} w_{j} u_{\sigma(j)}}=\frac{0.3 \times 8}{0.3 \times 8+0.4 \times 7+0.1 \times 5+0.2 \times 3}=0.381 .
$$

Similarly,

$$
\omega_{2}=0.445, \omega_{3}=0.079, \omega_{4}=0.095 \text {. }
$$

3. Compute the distance between $\alpha_{i}$ and $\beta_{i}$ using Equation (2) (note that we can get these distances directly from Example 1:

$$
d_{I F D}\left(\alpha_{1}, \beta_{1}\right)=0.1, d_{I F D}\left(\alpha_{2}, \beta_{2}\right)=0.2, d_{I F D}\left(\alpha_{3}, \beta_{3}\right)=0.55, d_{I F D}\left(\alpha_{4}, \beta_{4}\right)=0.25
$$

4. $\quad \operatorname{Rank} d_{I F D}\left(\alpha_{j}, \beta_{j}\right)(j=1,2,3,4)$ according to associated value of $u_{\sigma(j)}$ :

$$
\begin{gathered}
d_{I F D}\left(\alpha_{\sigma(1)}, \beta_{\sigma(1)}\right)=d_{I F D}\left(\alpha_{2}, \beta_{2}\right)=0.2, d_{I F D}\left(\alpha_{\sigma(2)}, \beta_{\sigma(2)}\right)=d_{I F D}\left(\alpha_{1}, \beta_{1}\right)=0.1 \\
d_{I F D}\left(\alpha_{\sigma(3)}, \beta_{\sigma(3)}\right)=d_{I F D}\left(\alpha_{4}, \beta_{4}\right)=0.25, d_{I F D}\left(\alpha_{\sigma(4)}, \beta_{\sigma(4)}\right)=d_{I F D}\left(\alpha_{3}, \beta_{3}\right)=0.55
\end{gathered}
$$

Employ the IFWIOWAD operator defined in Equation (5) to obtain the aggregation result:

$$
\operatorname{IFWIOWAD}(U, A, B)=0.381 \times 0.2+0.445 \times 0.1+0.079 \times 0.25+0.095 \times 0.55=0.1927 .
$$

It is easy to see that we get a different aggregation value compared to the IFIOWAD operator. In addition, the variables $u_{j}(j=1, \ldots, n)$ in the IFWIOWAD operator play dual functions, one is to induce the collection of arguments while the other moderates the weights that can overcome the drawback of the IFIOWAD operator caused by the limited role of the order-inducing variables.

Moreover, if the values of the order-inducing variables are changed to $U^{\prime}=(8,10,1,6)$, then we can recalculate the moderated weights:

$$
\omega_{1}=\frac{w_{1} u_{\sigma(1)}}{\sum_{j=1}^{4} w_{j} u_{\sigma(j)}}=\frac{0.3 \times 10}{0.3 \times 10+0.4 \times 8+0.1 \times 6+0.2 \times 1}=0.429 .
$$

Similarly,

$$
\omega_{2}=0.456, \omega_{3}=0.086, \omega_{4}=0.029 .
$$

Thus, the aggregation of the IFWIOWAD operator will yield the following result:

$$
\operatorname{IFWIOWAD}\left(U^{\prime}, A, B\right)=0.429 \times 0.2+0.456 \times 0.1+0.086 \times 0.25+0.029 \times 0.55=0.16885
$$

As can be seen, in comparison to the IFIOWAD operator, the aggregation result of the IFWIOWAD is changed based on the adjustment of the values of $u_{j}(j=1, \ldots, n)$, thus it can accommodate the variation caused by a change of order-inducing variables and yield better results.

Depending on the operational laws defined for the IFNs, one can drive some properties of the IFWIOWAD operator that are illustrated by the following theorems. 
Theorem 1. (Commutativity—distance measures). Let $\widetilde{F}$ be the IFWIOWAD operator, then

$$
\widetilde{F}\left(\left\langle u_{1}, \alpha_{1}, \beta_{1}\right\rangle, \ldots,\left\langle u_{n}, \alpha_{n}, \beta_{n}\right\rangle\right)=\widetilde{F}\left(\left\langle u_{1}, \beta_{1}, \alpha_{1}\right\rangle, \ldots,\left\langle u_{n}, \beta_{n}, \alpha_{n}\right\rangle\right)
$$

Theorem 2. (Commutativity-IOWA aggregation). Let $\left(\left\langle u_{1}, s_{1}, t_{1}\right\rangle, \ldots,\left\langle u_{n}, s_{n}, t_{n}\right\rangle\right)$ is any possible permutation of argument vector $\left(\left\langle u_{1}, \alpha_{1}, \beta_{1}\right\rangle, \ldots,\left\langle u_{n}, \alpha_{n}, \beta_{n}\right\rangle\right)$, then

$$
\widetilde{F}\left(\left\langle u_{1}, \alpha_{1}, \beta_{1}\right\rangle, \ldots,\left\langle u_{n}, \alpha_{n}, \beta_{n}\right\rangle\right)=\widetilde{F}\left(\left\langle u_{1}, s_{1}, t_{1}\right\rangle, \ldots,\left\langle u_{n}, s_{n}, t_{n}\right\rangle\right)
$$

Theorem 3. (Monotonicity). If $\left|\alpha_{i}-\beta_{i}\right| \leq\left|\alpha_{i}^{\prime}-\beta_{i}^{\prime}\right|$ for all $i$, then

$$
\widetilde{F}\left(\left\langle u_{1}, \alpha_{1}, \beta_{1}\right\rangle, \ldots,\left\langle u_{n}, \alpha_{n}, \beta_{n}\right\rangle\right) \leq \widetilde{F}\left(\left\langle u_{1}, s_{1}, t_{1}\right\rangle, \ldots,\left\langle u_{n}, s_{n}, t_{n}\right\rangle\right)
$$

Theorem 4. (Boundedness). Let $\min _{i}\left(\left|\alpha_{i}-\beta_{i}\right|\right)=d$ and $\max _{i}\left(\left(\left|\alpha_{i}-\beta_{i}\right|\right)\right)=D$, then

$$
d \leq \widetilde{F}\left(\left\langle u_{1}, \alpha_{1}, \beta_{1}\right\rangle, \ldots,\left\langle u_{n}, \alpha_{n}, \beta_{n}\right\rangle\right) \leq D
$$

Theorem 5. (Idempotency). If all $\widetilde{d_{i}}=\left|\alpha_{i}-\beta_{i}\right|=\widetilde{d}$ for all $i$, then

$$
\widetilde{F}\left(\left\langle u_{1}, \alpha_{1}, \beta_{1}\right\rangle, \ldots,\left\langle u_{n}, \alpha_{n}, \beta_{n}\right\rangle\right)=\widetilde{d}
$$

It is straightforward to prove these theorems and therefore omitted for sake of brevity. Moreover, some particular cases of the IFWIOWAD operator can be explored by analyzing the order-inducing values and the weight vector. For example,

- $\quad$ If $U=(u, 0, \cdots, 0)(u \neq 0)$, then

$$
\operatorname{IFWIOWAD}\left(\left\langle u_{1}, \alpha_{1}, \beta_{1}\right\rangle, \ldots,\left\langle u_{n}, \alpha_{n}, \beta_{n}\right\rangle\right)=d_{I F D}\left(\alpha_{\sigma(1)}, \beta_{\sigma(1)}\right)
$$

- If $U=(0, \cdots, 0, u)(u \neq 0)$, then

$$
\operatorname{IFWIOWAD}\left(\left\langle u_{1}, \alpha_{1}, \beta_{1}\right\rangle, \ldots,\left\langle u_{n}, \alpha_{n}, \beta_{n}\right\rangle\right)=d_{I F D}\left(\alpha_{\sigma(n)}, \beta_{\sigma(n)}\right)
$$

- $\quad$ If $w_{j}=0$ and $w_{k}=1$, for all $j \neq k$, then

$$
\operatorname{WIEOWD}\left(\left\langle u_{1}, p_{1}, q_{1}\right\rangle, \ldots,\left\langle u_{n}, p_{n}, q_{n}\right\rangle\right)=d_{I F D}\left(\alpha_{\sigma(k)}, \beta_{\sigma(k)}\right)
$$

Especially, if $D_{k}=\max _{i}\left\{\left|\alpha_{i}-\beta_{i}\right|\right\}$, then we get the intuitionistic fuzzy maximum distance; if $D_{k}=\min _{i}\left\{\left|\alpha_{i}-\beta_{i}\right|\right\}$, the intuitionistic fuzzy minimum distance.

Other a parameterized family of the IFWIOWAD operator can be described by similar methods, as applied in references [27-31].

\section{The IFWIOWAWAD Operator}

From the examples illustrated in the Section 3, we can see that the proposed IFWIOWAD operator can effectively eliminate the defects of the existing methods. However, further analysis indicates that the IFWIOWAD operator also has some shortcomings; i.e., it cannot integrate the weight of integrated arguments-and thus the importance of the integrated date cannot be reflected in the aggregation process. Recently, Merigó [32] presented a unification of the OWA and the IOWA operators, and termed it the induced ordered weighted averaging-weighted average (IOWAWA) 
operator. The prominent feature of the IOWAWA operator is that it unifies the IOWA operator and weighted average (WA) in the same formula, and allows each of the two concepts to be assigned a degree of importance in the aggregation. The IOWAWA operator has been receiving increasing attention to date. For example, Zeng et al. [33] explored the usefulness of the IOWAWA in the intuitionistic fuzzy situation. Merigó et al. [34] studied the application of the IOWAWA in entrepreneurial fuzzy group decision-making problems. Merigó et al. [35] presented some new IOWAWA-based methods to compute variance and covariance. Zeng et al. [36] proposed some aggregation operators based on the IOWAWA method in Pythagorean fuzzy environment. Motivated the idea of the IOWAWA operator, in this section we present the IFWIOWAWAD operator that comprises a unified model that employs the main advantages of IFWIOWAD operator and the weighted average (WA) methods. Thus, it can perform the importance of attributes and complex attitude of experts in the decision-making framework.

Definition 6. Let $A=\left(\alpha_{1}, \ldots, \alpha_{n}\right)$ and $B=\left(\beta_{1}, \ldots, \beta_{n}\right)$ be two sets of IFNs defined in set $Z=\left\{z_{1}, z_{2}, \ldots, z_{n}\right\}$ and $\delta_{i}$ be the weight of the element $z_{i}(i=1, \ldots, n)$, satisfying $\delta_{1}+\ldots+\delta_{n}=1$ and $\delta_{i} \in[0,1]$. Then, the IFWIOWAWAD is termed intuitionistic fuzzy weighted IOWA weighted average distance operator and defined as

$$
\operatorname{IFWIOWAWAD}\left(\left\langle u_{1}, \alpha_{1}, \beta_{1}\right\rangle, \ldots,\left\langle u_{n}, \alpha_{n}, \beta_{n}\right\rangle\right)=\sum_{j=1}^{n} \widetilde{w}_{j} d_{I F D}\left(\alpha_{\sigma(j)}, \beta_{\sigma(j)}\right)
$$

where $d_{I F D}\left(\alpha_{\sigma(j)}, \beta_{\sigma(j)}\right)$ is the argument value of $d_{I F D}\left(\alpha_{j}, \beta_{j}\right)$ reordered by the order-inducing variable $u_{\sigma(j)}$ such that $u_{\sigma(j-1)} \geq u_{\sigma(j)}$ for $1<j \leq n$. The combined weight of $\widetilde{w}$ is defined as follows:

$$
\widetilde{w}_{j}=\lambda \omega_{j}+(1-\lambda) \delta_{\sigma(j)}
$$

where $\lambda \in[0,1], W=\left(w_{1}, \ldots, w_{n}\right)^{T}$ is the associated weighting vector that simply satisfies the condition $0 \leq w_{j} \leq 1$ and $w_{1}+\ldots+w_{n}=1 . \omega_{j}$ is defined by Equation (6), that is

$$
\omega_{j}=\frac{w_{j} u_{\sigma(j)}}{\sum_{j=1}^{n} w_{j} u_{\sigma(j)}}
$$

The IFWIOWAWAD operator can also be explicitly illustrated in terms of the two underlying rules of aggregation (i.e., WA and IOWA). Thus, the IFWIOWAWAD can be separated into a linear combination of the IF weighted distance (IFWD) [15] and the IFWIOWAD:

$$
\begin{gathered}
\operatorname{IFWIOWAWAD}\left(\left\langle u_{1}, \alpha_{1}, \beta_{1}\right\rangle, \ldots,\left\langle u_{n}, \alpha_{n}, \beta_{n}\right\rangle\right)= \\
\lambda \sum_{j=1}^{n} \omega_{j} d_{I F D}\left(\alpha_{\sigma(j)}, \beta_{\sigma(j)}\right)+(1-\lambda) \sum_{i=1}^{n} \delta_{i} d_{I F D}\left(\alpha_{i}, \beta_{i}\right)
\end{gathered}
$$

Example 3. (Continuing from Example 2). Let the weighting vector $\delta=\left(\delta_{1}, \delta_{2}, \delta_{3}, \delta_{4}\right)^{T}=$ $(0.2,0.3,0.15,0.35)^{T}$ and $\lambda=0.6$, then with the help of Example 2, the rest steps using the IFWIOWAWAD operator are given as follows:

1. Compute the combined weight $\widetilde{w}_{j}(j=1,2,3,4)$ using Equation (16):

$$
\begin{gathered}
\widetilde{w}_{1}=\lambda \omega_{1}+(1-\lambda) \delta_{\sigma(1)}=0.6 \times 0.429+(1-0.6) \times 0.3=0.3774 \\
\widetilde{w}_{2}=\lambda \omega_{2}+(1-\lambda) \delta_{\sigma(2)}=0.6 \times 0.456+(1-0.6) \times 0.2=0.3536 \\
\widetilde{w}_{3}=\lambda \omega_{3}+(1-\lambda) \delta_{\sigma(3)}=0.6 \times 0.086+(1-0.6) \times 0.35=0.1916 \\
\widetilde{w}_{4}=\lambda \omega_{4}+(1-\lambda) \delta_{\sigma(4)}=0.6 \times 0.029+(1-0.6) \times 0.15=0.0774 .
\end{gathered}
$$


2. Employ the IFWIOWAWAD operator defined in Equation (15) to perform the aggregation as follows:

$\operatorname{IFWIOWAWAD}(U, A, B)=0.3774 \times 0.2+0.3536 \times 0.1+0.1916 \times 0.25+0.0774 \times 0.55=0.20131$

The aggregation of IFWIOWAWAD can also be performed using Equation (19) as following:

$$
\begin{gathered}
\text { IFWIOWAWAD }(U, A, B)=0.6 \times \operatorname{IFWIOWAD}+0.4 \times \text { IFWD } \\
=0.6 \times 0.16885+0.4 \times(0.2 \times 0.1+0.3 \times 0.2+0.15 \times 0.55+0.35 \times 0.25)=0.20131
\end{gathered}
$$

Evidently, we get the same aggregate values for both methods. Moreover, we can see that, contrary to the IFWIOWAD operator, the IFWIOWAWAD operator cannot only consider the attitudinal character represented by the order induced variable, but also take into account the importance of the argument based on the weighted average method.

In the following results, we show some of the most important properties of the IFWIOWAWAD operator.

Proposition 1. The IFWIOWAWAD is commutative if it follows (let $\varphi$ be the IFWIOWAWAD operator for a simple notation):

$$
\varphi\left(\left\langle u_{1}, \alpha_{1}, \beta_{1}\right\rangle, \ldots,\left\langle u_{n}, \alpha_{n}, \beta_{n}\right\rangle\right)=\varphi\left(\left\langle u_{1}, \beta_{1}, \alpha_{1}\right\rangle, \ldots,\left\langle u_{n}, \beta_{n}, \alpha_{n}\right\rangle\right)
$$

or

$$
\varphi\left(\left\langle u_{1}, \alpha_{1}, \beta_{1}\right\rangle, \ldots,\left\langle u_{n}, \alpha_{n}, \beta_{n}\right\rangle\right)=\varphi\left(\left\langle u_{1}, s_{1}, t_{1}\right\rangle, \ldots,\left\langle u_{n}, s_{n}, t_{n}\right\rangle\right)
$$

where $\left(\left\langle u_{1}, s_{1}, t_{1}\right\rangle, \ldots,\left\langle u_{n}, s_{n}, t_{n}\right\rangle\right)$ is a possible permutation of the argument vector $\left(\left\langle u_{1}, \alpha_{1}, \beta_{1}\right\rangle, \ldots,\left\langle u_{n}, \alpha_{n}, \beta_{n}\right\rangle\right)$.

Proposition 2. If $\left|\alpha_{i}-\beta_{i}\right| \leq\left|s_{1}-t_{1}\right|$ for all $i$, it follows that:

$$
\varphi\left(\left\langle u_{1}, \alpha_{1}, \beta_{1}\right\rangle, \ldots,\left\langle u_{n}, \alpha_{n}, \beta_{n}\right\rangle\right) \leq \varphi\left(\left\langle u_{1}, s_{1}, t_{1}\right\rangle, \ldots,\left\langle u_{n}, s_{n}, t_{n}\right\rangle\right)
$$

Then the IFWIOWAWAD is monotonic.

Proposition 3. The IFWIOWAWAD is bounded if it follows that:

$$
\min _{i}\left(\left|\alpha_{i}-\beta_{i}\right|\right) \leq \varphi\left(\left\langle u_{1}, \alpha_{1}, \beta_{1}\right\rangle, \ldots,\left\langle u_{n}, \alpha_{n}, \beta_{n}\right\rangle\right) \leq \max _{i}\left(\left|\alpha_{i}-\beta_{i}\right|\right)
$$

Proposition 4. If all $\widetilde{d_{i}}=\left|\alpha_{i}-\beta_{i}\right|=\widetilde{d}$ for $i \in[1, n]$, it follows that:

$$
\widetilde{F}\left(\left\langle u_{1}, \alpha_{1}, \beta_{1}\right\rangle, \ldots,\left\langle u_{n}, \alpha_{n}, \beta_{n}\right\rangle\right)=\widetilde{d}
$$

Then the IFWIOWAWAD operator is idempotent.

By selecting different values for the weights and parameters in the IFWIOWAWAD operator, we can derive some special intuitionistic fuzzy distance operators. For example:

- When $\lambda=1$, the IFWIOWAWAD reduces to the IFWIOWAD operator.

- When $\lambda=0$, we get the IFWD operator.

Equivalently, many other special cases can be derived by analyzing the weighting vectors $W, V$ and the order inducing variable vector $U$ in a similar way (see [33-36]). 


\section{A MADM Model Based on the IFWIOWAWAD Operator}

A framework of the MADM model based on the IFWIOWAWAD is presented in this section. The main process for the model is structured as follows:

Step 1. Each decision maker $e_{k}$ provides their opinions and thus forms the individual decision matrix, constructed as in (24):

$$
D_{k}=\begin{array}{ccc}
C_{1} & \cdots & C_{n} \\
A_{1} \\
\vdots \\
A_{n}
\end{array}\left(\begin{array}{ccc}
\alpha_{11}^{(k)} & \cdots & \alpha_{1 n}^{(k)} \\
\vdots & \ddots & \vdots \\
\alpha_{m 1}^{(k)} & \cdots & \alpha_{m n}^{(k)}
\end{array}\right)
$$

where $A_{i}$ and $C_{j}$ indicate the alternative $i(i=1, \ldots, m)$ and the attribute $j(j=1, \ldots, n)$, respectively. Meanwhile the IFNs $\alpha_{i j}^{(k)}=\left(\mu_{i j}^{(k)}, v_{i j}^{(k)}\right)$ represents the preference for $A_{i}$ with respect to the attribute $C_{j}$.

Step 2. Employ the IF weighted average (IFWA) operator [24] to convert individual opinions of each decision makers into a group decision matrix $D=\left(\alpha_{i j}\right)_{m \times n^{\prime}}$, where

$$
\alpha_{i j}=\operatorname{IFWA}\left(\alpha_{i j}^{(1)}, \ldots, \alpha_{i j}^{(t)}\right) i=1, \ldots, m, j=1, \ldots, n .
$$

Step 3. Construct the ideal alternative $I$ and determine the order-inducing variables and weights used for the IFWIOWAWAD operator.

Step 4. Compute the weighted distance between the ideal alternative $I$ and each $A_{i}(i=1, \ldots, 5)$ using the IFWIOWAWAD operator.

Step 5. Establish a ranking for the alternative $A_{i}(i=1, \ldots, 5)$ in accordance with the IFWIOWAWAD $\left(I, A_{i}\right)$ obtained in step 4 . The alternative with the smallest distance will be selected as the best.

\section{An Example of Investment Selection}

Decision-making related to the selection of a suitable investment from finite feasible alternatives constitutes one of the most common and important activities in various business fields. The complexity of the assessment and selection process for investment projects necessitates a complex method: i.e., the multiple attribute decision-making (MADM) technique provides an efficient tool for decision makers to solve problems based on an evaluation or preference information given by multiple experts. In the past, many authors have proposed different MADM approaches for solving the selection of investment problems [37-41]. Previous findings have shown that the applications of the induced aggregation distance operators are very heartening and widely used in the decision-making process. This paper presents the application of the proposed model in the process of selecting investments in which a group of decision makers (or experts) are invited for the selection of a suitable strategy (adapted from Ref. [32]). Based on the market research and preliminary screening, there are five companies (alternatives) to be considered as potential investment options, namely a chemical company $\left(A_{1}\right)$, a food company $\left(A_{2}\right)$, a car company $\left(A_{3}\right)$, a furniture company $\left(A_{4}\right)$ and a computer company $\left(A_{5}\right)$. The main situations of company for investment are evaluated by the world economic growth rate: $C_{1}=$ High growth rate, $C_{2}=$ Medium growth rate, $C_{3}=$ Low growth rate, $C_{4}=$ Growth rate near 0 and $C_{5}=$ Negative growth rate. The assessment of the alternatives with respect to each attribute given by three decision makers, are given in Tables $2-4$. For example, the decision maker $e_{1}$ called ten experts together to assess the situations (attributes) for these five companies. As for the $C_{1}$ of the company $A_{1}$, if six experts consider $C_{1}$ strong while three experts consider $C_{1}$ low and one expert do not judge whether $C_{1}$ is strong or not, then the evaluation of company $A_{1}$ relative to $C_{1}$ can be represented by $\operatorname{IFN}(0.6,0.3)$ by using the statistical approach. 
Table 2. Decision matrix $D_{1}$.

\begin{tabular}{cccccc}
\hline Alternatives & $C_{1}$ & $C_{2}$ & $C_{3}$ & $C_{4}$ & $C_{5}$ \\
\hline$A_{1}$ & $(0.2,0.6)$ & $(0.5,0.3)$ & $(0.4,0.4)$ & $(0.5,0.4)$ & $(0.3,0.5)$ \\
$A_{2}$ & $(0.6,0.2)$ & $(0.7,0.3)$ & $(0.6 .0 .2)$ & $(0.7,0.2)$ & $(0.4,0.5)$ \\
$A_{3}$ & $(0.6,0.2)$ & $(0.6,0.4)$ & $(0.5,0.3)$ & $(0.6,0.3)$ & $(0.4,0.4)$ \\
$A_{4}$ & $(0.4,0.2)$ & $(0.7,0.2)$ & $(0.5,0.2)$ & $(0.4,0.4)$ & $(0.6,0.3)$ \\
$A_{5}$ & $(0.7,0.3)$ & $(0.4,0.3)$ & $(0.6,0.3)$ & $(0.5,0.4)$ & $(0.6,0.2)$ \\
\hline
\end{tabular}

Table 3. Decision matrix $D_{2}$.

\begin{tabular}{cccccc}
\hline Alternatives & $C_{1}$ & $C_{2}$ & $C_{3}$ & $C_{4}$ & $C_{5}$ \\
\hline$A_{1}$ & $(0.5,0.3)$ & $(0.7,0.2)$ & $(0.5,0.4)$ & $(0.7,0.3)$ & $(0.4,0.3)$ \\
$A_{2}$ & $(0.7,0.2)$ & $(0.6,0.2)$ & $(0.8,0.1)$ & $(0.5,0.4)$ & $(0.6,0.2)$ \\
$A_{3}$ & $(0.4,0.4)$ & $(0.4,0.4)$ & $(0.4,0.2)$ & $(0.6,0.3)$ & $(0.4,0.4)$ \\
$A_{4}$ & $(0.6,0.2)$ & $(0.6,0.2)$ & $(0.7,0.2)$ & $(0.6,0.2)$ & $(0.5,0.3)$ \\
$A_{5}$ & $(0.8,0.2)$ & $(0.5,0.3)$ & $(0.6,0.1)$ & $(0.6,0.2)$ & $(0.6,0.2)$ \\
\hline
\end{tabular}

Table 4. Decision matrix $D_{3}$.

\begin{tabular}{cccccc}
\hline Alternatives & $C_{1}$ & $C_{2}$ & $C_{3}$ & $C_{4}$ & $C_{5}$ \\
\hline$A_{1}$ & $(0.6,0.2)$ & $(0.8,0.2)$ & $(0.7,0.2)$ & $(0.6,0.3)$ & $(0.5,0.4)$ \\
$A_{2}$ & $(0.7,0.3)$ & $(0.6,0.2)$ & $(0.3,0.4)$ & $(0.7,0.1)$ & $(0.8,0.2)$ \\
$A_{3}$ & $(0.8,0.1)$ & $(0.7,0.2)$ & $(0.7,0.1)$ & $(0.3,0.4)$ & $(0.6,0.3)$ \\
$A_{4}$ & $(0.5,0.5)$ & $(0.3,0.4)$ & $(0.6,0.2)$ & $(0.4,0.5)$ & $(0.5,0.2)$ \\
$A_{5}$ & $(0.6,0.3)$ & $(0.8,0.2)$ & $(0.6,0.2)$ & $(0.5,0.3)$ & $(0.7,0.2)$ \\
\hline
\end{tabular}

In this problem, the weighting vector of the three experts is assumed to $V=(0.3,0.4,0.3)^{T}$ while, the collective results performed by the IFWA operator are listed in Table 5.

Table 5. Collective decision matrix $D$.

\begin{tabular}{cccccc}
\hline Alternatives & $C_{1}$ & $C_{2}$ & $C_{3}$ & $C_{4}$ & $C_{5}$ \\
\hline$A_{1}$ & $(0.46,0.33)$ & $(0.69,0.26)$ & $(0.55,0.32)$ & $(0.62,0.33)$ & $(0.41,0.38)$ \\
$A_{2}$ & $(0.67,0.23)$ & $(0.63,0.23)$ & $(0.64,0.19)$ & $(0.63,0.21)$ & $(0.63,0.26)$ \\
$A_{3}$ & $(0.68,0.20)$ & $(0.59,0.23)$ & $(0.54,0.18)$ & $(0.53,0.33)$ & $(0.47,0.37)$ \\
$A_{4}$ & $(0.43,0.26)$ & $(0.57,0.25)$ & $(0.62,0.20)$ & $(0.49,0.32)$ & $(0.53,0.27)$ \\
$A_{5}$ & $(0.72,0.26)$ & $(0.60,0.27)$ & $(0.60,0.17)$ & $(0.54,0.22)$ & $(0.63,0.20)$ \\
\hline
\end{tabular}

The order-inducing variables and the ideal alternative determined by the group of experts are shown in Tables 6 and 7, respectively.

Table 6. Order-inducing variables.

\begin{tabular}{cccccc}
\hline Varaible & $C_{1}$ & $C_{2}$ & $C_{3}$ & $C_{4}$ & $C_{5}$ \\
\hline$U$ & 0.8 & 0.9 & 0.4 & 0.7 & 0.6 \\
\hline
\end{tabular}

Table 7. Ideal alternative.

\begin{tabular}{cccccc}
\hline Ideal Alternative & $C_{1}$ & $C_{2}$ & $C_{3}$ & $C_{4}$ & $C_{5}$ \\
\hline$I$ & $(0.8,0.1)$ & $(0.9,0.1)$ & $(0.9,0)$ & $(0.8,0.1)$ & $(0.9,0.1)$ \\
\hline
\end{tabular}


The weights $\delta_{i}$ for the attributes are given as $0.1,0.25,0.2,0.35,0.1$ while the ordered weights, $w_{j}$ are assumed to be $0.15,0.25,0.2,0.1,0.3$. Table 8 shows the aggregated results performed by the IFWIOWAWAD operator $(\lambda=0.4)$.

Table 8. Aggregate results and ranking rendered by the IFWIOWAWAD operator.

\begin{tabular}{cccccc}
\hline Results & $A_{1}$ & $A_{2}$ & $A_{3}$ & $A_{4}$ & $A_{5}$ \\
\hline IFWIOWAWAD $\left(A_{i}, I\right)$ & 0.25745 & 0.187427 & 0.231064 & 0.25484 & 0.195926 \\
Ranking & 5 & 1 & 3 & 4 & 2 \\
\hline
\end{tabular}

Thus, $A_{2}$ appears to be the best choice as it is closest to the ideal alternative while, the ranking of the five alternatives is $A_{2} \succ A_{5} \succ A_{3} \succ A_{4} \succ A_{1}$.

To conduct a comparative analysis, we employ the IFIOWAWAD and IFOWAWAD operators in identical decision information to further explore the effectiveness of the order-inducing variables on the aggregation results. The results are shown in Table 9.

Thus, the rankings of the alternatives obtained by the IFIOWAWAD and IFOWAWAD operators are $A_{2} \succ A_{5} \succ A_{3} \succ A_{1} \succ A_{4}$ and $A_{5} \succ A_{2} \succ A_{3} \succ A_{4} \succ A_{1}$, respectively. From Tables 8 and 9, it is clear that the orderings of the alternatives may change if a different distance operator is used. It should be pointed out that the order-inducing variables in the IFIOWAWAD operator only perform a single induced function during the aggregation process. The IFOWAWAD operator integrates the importance of attributes and ordered weights into the formula to evaluate the IFS information, but fails to account for the attitudinal characters as it cannot infuse the order-inducing variables. However, the IFWIOWAWAD not only integrates both of the weights, but also captures the variation in the order-inducing variables, and thus achieves a more scientific and accurate result in comparison with other approaches.

Table 9. Aggregate results driven by the IFIOWAWAD and the IFOWAWAD operators.

\begin{tabular}{cccccc}
\hline Results & $\boldsymbol{A}_{1}$ & $\boldsymbol{A}_{2}$ & $\boldsymbol{A}_{3}$ & $\boldsymbol{A}_{4}$ & $\boldsymbol{A}_{5}$ \\
\hline IFIOWAWAD $\left(A_{i}, I\right)$ & 0.265624 & 0.182068 & 0.213909 & 0.275726 & 0.185689 \\
IFOWAWAD $\left(A_{i}, I\right)$ & 0.261 & 0.1975 & 0.2355 & 0.25085 & 0.19625 \\
\hline
\end{tabular}

Moreover, it is possible to conduct a sensitive analysis to explore the robustness of the ranking of the alternative with regards to the parameter $\lambda, \lambda \in[0,1]$. The computation results are illustrated in Table 10.

Table 10. Ranking rendered by the IFWIOWAWAD operator with different values of $\lambda$.

\begin{tabular}{cl}
\hline$\lambda$ & Ranking of Alternative \\
\hline$\lambda=0$ & $A_{2} \succ A_{5} \succ A_{3} \succ A_{1} \succ A_{4}$ \\
$\lambda=0.1$ & $A_{2} \succ A_{5} \succ A_{3} \succ A_{1} \succ A_{4}$ \\
$\lambda=0.2$ & $A_{2} \succ A_{5} \succ A_{3} \succ A_{4} \succ A_{1}$ \\
$\lambda=0.3$ & $A_{2} \succ A_{5} \succ A_{3} \succ A_{4} \succ A_{1}$ \\
$\lambda=0.4$ & $A_{2} \succ A_{5} \succ A_{3} \succ A_{4} \succ A_{1}$ \\
$\lambda=0.5$ & $A_{2} \succ A_{5} \succ A_{3} \succ A_{4} \succ A_{1}$ \\
$\lambda=0.6$ & $A_{2} \succ A_{5} \succ A_{3} \succ A_{4} \succ A_{1}$ \\
$\lambda=0.7$ & $A_{2} \succ A_{5} \succ A_{3} \succ A_{4} \succ A_{1}$ \\
$\lambda=0.8$ & $A_{2} \succ A_{5} \succ A_{3} \succ A_{4} \succ A_{1}$ \\
$\lambda=0.9$ & $A_{2} \succ A_{5} \succ A_{3} \succ A_{4} \succ A_{1}$ \\
$\lambda=1$ & $A_{5} \succ A_{2} \succ A_{3} \succ A_{4} \succ A_{1}$ \\
\hline
\end{tabular}

As can be seen, the ranking of alternatives may be different based on the different values of $\lambda$. Thus, the decision maker can select suitable values of $\lambda$ to meet their interests or actual needs at hand. 
Therefore, this model is rather flexible as it provides more choices to decision makers for the selection of aggregation schemes by adjusting different values of the parameters.

\section{Conclusions}

To effectively deal with and process intuitionistic fuzzy information, in this study we have proposed the intuitionistic fuzzy weighted induced ordered weighted averaging distance operator, which improves the existing aggregation operators by extending the role of the order-inducing variables. In the proposed operator, the order-inducing variables induce the order of arguments and moderate the associated weights simultaneously. Thus, it enables us to capture the variations in the final aggregation results caused by the order-inducing variables. A generation of intuitionistic fuzzy weighted induced ordered weighted averaging distance operator has been further developed, based on which, a novel model for intuitionistic fuzzy multiple attribute decision making problems was developed. This model presents a useful and adaptable way to integrate subjective opinions and complex attitudinal characters in real situations. The comparative analysis illustrates that this model is expected to lead to more realistic and accurate results in intuitionistic fuzzy situations. Thus, this paper offers a significant contribution in regards to the development of MADM frameworks for investment selection problems.

In future research efforts, we will consider extending the approach with probabilities or other kinds of distance measures. We may also consider other situations based on the presented procedures and tools, such as the Pythagorean fuzzy set $[36,42]$ and Neutrosophic set $[43,44]$.

Author Contributions: Z.L. drafted the initial manuscript and conceived the MADM framework. D.S. provided the relevant literature review and the illustrated example. S.Z. revised the manuscript and analyzed the data.

Funding: This paper is supported by National Social Science Fund of China (No.18BTJ027).

Conflicts of Interest: The authors declare no conflict of interest.

\section{References}

1. Atanassov, K. Intuitionistic fuzzy sets. Fuzzy Sets Syst. 1986, 20, 87-96. [CrossRef]

2. Yu, D.J.; Liao, H.C. Visualization and quantitative research on intuitionistic fuzzy studies. J. Intell. Fuzzy Syst. 2016, 30, 3653-3663. [CrossRef]

3. Yu, D.J.; Shi, S.S. Researching the development of Atanassov intuitionistic fuzzy set: Using a citation network analysis. Appl. Soft Comput. 2015, 32, 189-198. [CrossRef]

4. Mehdi, K.G.; Maghsoud, A.; Edmundas, K.Z.; Jurgita, A. Supplier evaluation and selection in fuzzy environments: A review of MADM approaches. Econ. Res. Ekon. Istraž. 2017, 30, 1073-1118.

5. Shen, F.; Ma, X.S.; Li, Z.; Xu, Z.S.; Cai, D.L. An extended intuitionistic fuzzy TOPSIS method based on a new distance measure with an application to credit risk evaluation. Inf. Sci. 2018, 428, 105-119. [CrossRef]

6. Song, Y.F.; Wang, X.D.; Zhang, H.L. A distance measure between intuitionistic fuzzy belief functions. Knowl.-Based Syst. 2015, 86, 288-298. [CrossRef]

7. Zhang, H.M.; Yu, L.Y. New distance measures between intuitionistic fuzzy sets and interval-valued fuzzy sets. Inf. Sci. 2013, 245, 181-196. [CrossRef]

8. Hung, W.L.; Yang, M.S. Similarity measures of intuitionistic fuzzy sets based on Hausdorff distance. Pattern Recognit. Lett. 2004, 25, 1603-1611. [CrossRef]

9. Zeng, S.Z.; Su, W.H. Intuitionistic fuzzy ordered weighted distance operator. Knowl.-Based Syst. 2011, 24, 1224-1232. [CrossRef]

10. Zeng, S.Z.; Xiao, Y. TOPSIS method for intuitionistic fuzzy multiple-criteria decision making and its application to investment selection. Kybernetes 2016, 45, 282-296. [CrossRef]

11. Merigó, J.M.; Casanovas, M. Decision making with distance measures and induced aggregation operators. Comput. Ind. Eng. 2011, 60, 66-76. [CrossRef]

12. Zeng, S.Z.; Merigó, J.M.; Palacios-Marques, D.; Jin, H.H.; Gu, F.J. Intuitionistic fuzzy induced ordered weighted averaging distance operator and its application to decision making. J. Intell. Fuzzy Syst. 2017, 32, 11-22. [CrossRef] 
13. Merigó, J.M.; Casanovas, M. A new Minkowski distance based on induced aggregation operators. Int. J. Comput. Intell. Syst. 2011, 4, 123-133. [CrossRef]

14. Casanovas, M.; Torres-Martínez, A.; Merigó, J.M. Decision making in reinsurance with induced OWA operators and Minkowski distances. Cybern. Syst. 2016, 47, 460-477. [CrossRef]

15. Merigó, J.M.; Casanovas, M. Induced aggregation operators in the Euclidean distance and its application in financial decision making. Expert Syst. Appl. 2011, 38, 7603-7608. [CrossRef]

16. Zeng, S.Z.; Li, W.; Merigó, J.M. Extended induced ordered weighted averaging distance operators and their application to group decision-making. Int. J. Inf. Technol. Decis. Mak. 2013, 12, 1973-6845. [CrossRef]

17. Su, W.H.; Zeng, S.Z.; Ye, X.J. Uncertain group decision-making with induced aggregation operators and Euclidean distance. Technol. Econ. Dev. Econ. 2013, 19, 431-447. [CrossRef]

18. Zeng, S.Z.; Su, W.H.; Chen, J. Fuzzy decision making with induced heavy aggregation operators and distance measures. J. Intell. Fuzzy Syst. 2014, 26, 127-135.

19. Li, C.G.; Zeng, S.Z.; Pan, T.J.; Zheng, L.N. A method based on induced aggregation operators and distance measures to multiple attribute decision making under 2-tuple linguistic environment. J. Comput. Syst. Sci. 2014, 80, 1339-1349. [CrossRef]

20. Xian, S.D.; Sun, W.J. Fuzzy linguistic induced euclidean OWA distance operator and its application in group linguistic decision making. Int. J. Intell. Syst. 2014, 29, 478-491. [CrossRef]

21. Su, W.; Zhang, C.; Zeng, S. Uncertain induced heavy aggregation distance operator and its application to decision making. Cybern. Syst. 2015, 46, 172-187. [CrossRef]

22. Xian, S.D.; Sun, W.J.; Xu, S.H.; Gao, Y.Y. Fuzzy linguistic induced OWA Minkowski distance operator and its application in group decision making. Pattern Anal. Appl. 2016, 19, 325-335. [CrossRef]

23. Xue, W.T.; Xian, S.D.; Dong, Y.F. A novel intuitionistic fuzzy induced ordered weighted Euclidean distance operator and its application for group decision making. Int. J. Intell. Syst. 2017, 32, 739-753. [CrossRef]

24. Xu, Z.S. Intuitionistic fuzzy aggregation operators. IEEE Trans. Fuzzy Syst. 2007, 15, 1179-1187.

25. Yager, R.R. On ordered weighted averaging aggregation operators in multi-criteria decision making. IEEE Trans. Syst. Man Cybern. B 1988, 18, 183-190. [CrossRef]

26. Yager, R.R.; Filev, D.P. Induced ordered weighted averaging operators. IEEE Trans. Syst. Man Cybern. Part B 1999, 29, 141-150. [CrossRef] [PubMed]

27. Aggarwal, M. A New Family of Induced OWA Operators. Int. J. Intell. Syst. 2015, 30, 170-205. [CrossRef]

28. Zeng, S.Z. Pythagorean fuzzy multiattribute group decision making with probabilistic information and OWA approach. Int. J. Intell. Syst. 2017, 32, 1136-1150. [CrossRef]

29. Merigó, J.M.; Palacios-Marqués, D.; Soto-Acosta, P. Distance measures, weighted averages, OWA operators and Bonferroni means. Appl. Soft Comput. 2017, 50, 356-366. [CrossRef]

30. Zeng, S.Z.; Xiao, Y. A method based on TOPSIS and distance measures for hesitant fuzzy multiple attribute decision making. Technol. Econ. Dev. Econ. 2018, 24, 969-983. [CrossRef]

31. Zeng, S.Z.; Wang, N.; Zhang, C.H.; Su, W.H. A novel method based on induced aggregation operator for classroom teaching quality evaluation with probabilistic and Pythagorean fuzzy information. Eurasia J. Math. Sci. Technol. Educ. 2018, 14, 3205-3212. [CrossRef]

32. Merigó, J.M. A unified model between the weighted average and the induced OWA operator. Expert Syst. Appl. 2011, 38, 11560-11572. [CrossRef]

33. Zeng, S.Z.; Wang, Q.; Merigó, J.M.; Pan, T. Induced intuitionistic fuzzy ordered weighted averaging-Weighted average operator and its application to business decision-making. Comput. Sci. Inf. Syst. 2014, 11, 839-857.

34. Merigó, J.M.; Peris-Ortiz, M.; Palacios-Marqués, D. Entrepreneurial fuzzy group decision-making under complex environments. J. Intell. Fuzzy Syst. 2014, 27, 901-912.

35. Merigó, J.M.; Guillén, M.; Sarabia, J.M. The ordered weighted average in the variance and the covariance. Int. J. Intell. Syst. 2015, 30, 985-1005. [CrossRef]

36. Zeng, S.Z.; Mu, Z.M.; Baležentis, T. A novel aggregation method for Pythagorean fuzzy multiple attribute group decision making. Int. J. Intell. Syst. 2018, 33, 573-585. [CrossRef]

37. Renna, P. A Decision Investment Model to Design Manufacturing Systems based on a genetic algorithm and Monte-Carlo simulation. Int. J. Comput. Integr. Manuf. 2017, 30, 590-605. [CrossRef] 
38. Chatterjee, P.; Mondal, S.; Boral, S.; Banerjee, A.; Chakraborty, S. A novel hybrid method for non-traditional machining process selection using factor relationship and multi-attributive border approximation method. Facta Univ. Ser. Mech. Eng. 2017, 15, 439-456. [CrossRef]

39. Petkovic, D.; Madic, M.; Radovanovic, M.; Gecevska, V. Application of the performance selection index method for solving machining MCDM problems. Facta Univ. Ser. Mech. Eng. 2017, 15, 97-106. [CrossRef]

40. Roy, J.; Adhikary, K.; Kar, S.; Pamučar, D. A rough strength relational DEMATEL model for analysing the key success factors of hospital service quality. Decis. Mak. Appl. Manag. Eng. 2018, 1, 121-142. [CrossRef]

41. Vasiljević, M.; Fazlollahtabar, H.; Stević, Ž.; Vesković, S. A rough multicriteria approach for evaluation of the supplier criteria in automotive industry. Decis. Mak. Appl. Manag. Eng. 2018, 1, 82-96. [CrossRef]

42. Zhang, X.L.; Xu, Z.S. Extension of TOPSIS to multiple criteria decision making with Pythagorean fuzzy sets. Int. J. Intell. Syst. 2014, 29, 1061-1078. [CrossRef]

43. Ye, J. Multiple attribute decision-making method using correlation coefficients of normal Neutrosophic sets. Symmetry 2017, 9, 80. [CrossRef]

44. Wang, J.; Wei, G.W.; Wei, Y. Models for green supplier selection with some 2-tuple linguistic Neutrosophic number Bonferroni mean operators. Symmetry 2018, 10, 131. [CrossRef]

(C) 2018 by the authors. Licensee MDPI, Basel, Switzerland. This article is an open access article distributed under the terms and conditions of the Creative Commons Attribution (CC BY) license (http:/ / creativecommons.org/licenses/by/4.0/). 